\title{
Gemtuzumab ozogamicin in the treatment of adult acute myeloid leukemia
}

\author{
Hiroko Tsunemine, Takayuki Takahashi\# \\ Department of Hematology, Shinko Hospital, Kobe, Japan; ${ }^{\#}$ Corresponding Author: takahashi.takayuki@shinkohp.or.jp
}

Received 14 March 2013; revised 15 April 2013; accepted 1 May 2013

Copyright (C) 2013 Hiroko Tsunemine, Takayuki Takahashi. This is an open access article distributed under the Creative Commons Attribution License, which permits unrestricted use, distribution, and reproduction in any medium, provided the original work is properly cited.

\begin{abstract}
Gemtuzumab ozogamicin (GO) is a humanized anti-CD33 monoclonal antibody conjugated to a derivative of an antitumor antibiotic, calicheamicin. GO was approved for the treatment of relapsed acute myeloid leukemia (AML) in the United States (US) in 2000. However, GO was withdrawn from the US market in June 2010, because a large-scale clinical trial failed to show additive or synergistic effects with conventional chemotherapy for newly diagnosed AML. GO is currently available only in Japan. However, several large clinical studies have demonstrated beneficial effects of GO when added to chemotherapy for $A M L$ in recent years; therefore, reconsideration of GO availability is gaining attention. Therefore, the role and efficacy of GO as monotherapy or in combination therapy for de novo or relapsed AML should be positively investigated.
\end{abstract}

Keywords: Gemtuzumab Ozogamicin; Acute Myeloid Leukemia; Acute Promyelocytic Leukemia; Monotherapy; Combination Chemotherapy; Sinusoidal Obstruction Syndrome; Veno-Occlusive Disease

\section{INTRODUCTION}

\section{Gemtuzumab Ozogamicin On and Off}

Acute myeloid leukemia (AML) is the most common subtype of acute leukemia in adults. The incidence of AML is higher in elderly people 65 years of age or older, and the median age at onset is approximately 62 to 64 years $[1,2]$. Conventional chemotherapy results in complete remission in more than $70 \%$ of patients younger

"Disclosure: We have no conflicts of interest with regard to any companies or individuals. than 65 years of age [3-5], and the proportion of longterm survivors has improved to $30 \%-40 \%$ of all AML patients in past decades. Although chemotherapy regimens for AML have remained mostly unchanged over the last 30 years, supportive care, including antimicrobial agents and blood component transfusions, has been significantly improved, enabling the use of more intensive chemotherapies. Among elderly AML patients, however, therapeutic outcomes are less satisfactory; approximate $40 \%$ to $65 \%$ of elderly AML patients achieve complete remission, although $85 \%$ of them relapse within two to three years [6-8].

Gemtuzumab ozogamicin (GO) is an anti-CD33 monoclonal antibody that is conjugated to a cytotoxic agent, calicheamicin [9]. CD33 is expressed in approximately $90 \%$ of myeloblasts in patients with AML, as defined by the presence of the antigen on more than $20 \%$ of leukemic blast cells [10]. GO is rapidly internalized after binding to CD33 on the cell surface. The endocytosed antiCD33 complex translocates to the lysosome, then the acidic environment of the component causes the release of a calicheamicin derivative resulting in double-strand breaks in DNA and ultimately cell death [11].

In May 2000, the United States (US) Food and Drug Administration (FDA) granted approval for the use of GO to treat AML patients in a first relapse who are 60 years of age or older or are not indicated for chemotherapy of standard intensity $[12,13]$. Following the US approval, GO was approved in Europe and Japan to treat AML patients with this same status [14]. However, a required post-approval study (SWOGS01016) that evaluated GO combined with conventional chemotherapy for newly diagnosed AML patients under 61 years of age failed to confirm any clinical benefits and instead demonstrated an increased rate of treatment-related mortality [15]. These results prompted Pfizer, Inc. to voluntarily withdraw GO from the US market in 2010, before the results of other randomized trials were made available. 
However, in recent years, several prospective randomized trials of elderly de novo AML patients have demonstrated a statistically significant survival advantage for patients who receive GO [16-18]. Therefore, the efficacy of $\mathrm{GO}$ is currently being reevaluated.

\section{GO IN THE TREATMENT OF AML AS A MONOTHERAPEUTIC AGENT}

\subsection{Recommended Dosage of GO}

Based on the results obtained in a phase I dose escalation trial for relapsed or refractory CD33-positive AML, the recommended dosage of GO as monotherapy is $9 \mathrm{mg}$ / $\mathrm{m}^{2}$ twice with an interval of at least 14 days [19]. This dosage was determined in a phase II study based on the rationale that more than $75 \%$ of CD33 sites are consistently saturated with GO at this dose. This dosage regimen was also considered to contain a tolerable dose level in terms of hematologic toxicity in a phase I study [12, $13,19]$.

\subsection{GO as a Monotherapeutic Agent and Its Efficacy for AML}

Three open-label, multicenter phase II studies were conducted to evaluate the efficacy and safety of singleagent GO in the treatment of patients with AML at the first recurrence [13]. These studies included 277 patients with a median age of 61 years. The overall response rate was $26 \%$ of the enrolled patients, with a $13 \%$ complete remission (CR) rate and a $13 \% \mathrm{CR}$ with incomplete platelet recovery $(\mathrm{CRp})$ rate. The median recurrence-free survival was 6.4 and 4.5 months for patients who achieved a CR and CRp, respectively. These interim results led to the approval of GO by the FDA for the treatment of patients with CD33-positive AML in a first recur- rence who are 60 years of age or older and are not candidates for cytotoxic chemotherapy [20]. A number of studies of relapsed, refractory and untreated AML have been performed (Table 1). The overall response rates range from $17 \%$ to $33 \%$ [12,21-25]. These results suggest that $\mathrm{GO}$ as a monotherapeutic agent exhibits limited efficacy for all types of AML, except for acute promyelocytic leukemia (APL).

\subsection{Adverse Effects of $G O$}

Regardless of the indications for GO in AML patients who are not candidates for intensive chemotherapy, myelosuppression is observed in the majority of patients treated solely with GO. Although grade 3 to 4 neutropenia $(98 \%)$ and thrombocytopenia (99\%) have been observed, the incidence rates of grade 3 to 4 sepsis (17\%) and pneumonia (8\%) are relatively low [13]. Grade 3 to 4 hyperbilirubinemia develops in $29 \%$ of patients and elevated serum transaminase levels are observed in $18 \%$ of patients, presumably due to dissociation of calicheamicin during the intrahepatic metabolism of GO [13]. GO is associated with less gastrointestinal toxicity than anthracyclines or cytarabine; however, it is distinctively associated with hepatic sinusoidal obstruction syndrome (SOS)/ veno-occlusive disease (VOD) [26]. The incidence of SOS has been reported to be only $0.9 \%$ among patients who do not undergo prior or subsequent allogeneic hematopoietic cell transplantation (HSCT) [13]; however, 5\% of patients who undergo allogeneic HSCT within three months after GO administration develop SOS [20]. The use of fractionated dosing with a reduced total dose of GO exhibits similar therapeutic efficacy; therefore, this protocol has the potential to reduce the incidence of SOS $[21,23]$.

Table 1. Gemtuzumab ozogamicin as a monotherapeutic agent in acute myeloid leukemia patients.

\begin{tabular}{|c|c|c|c|c|c|c|c|}
\hline Reference & $\begin{array}{l}\text { Number of } \\
\text { patients }\end{array}$ & $\begin{array}{l}\text { Median age } \\
\text { (range) }\end{array}$ & AML status & Dose and schedule & $\begin{array}{c}\text { CR/CRp } \\
(\%)\end{array}$ & RFS & OS \\
\hline Sievers et al. (12) & 142 & $61(22-84)$ & First relapse AML & $9 \mathrm{mg} / \mathrm{m}^{2} \mathrm{D} 1$ and $\mathrm{D} 15$ & $16 / 13$ & $6.8 \mathrm{mo}$ & $5.9 \mathrm{mo}$ \\
\hline Taksin et al. (21) & 57 & $64(22-80)$ & First relapse AML & $3 \mathrm{mg} / \mathrm{m}^{2} \mathrm{D} 1,4$, and 7 & $26 / 7$ & $11.0 \mathrm{mo}$ & $8.4 \mathrm{mo}$ \\
\hline Piccaluga et al.(22) & 24 & $63(20-75)$ & Relapsed, refractory AML & 6 or $9 \mathrm{mg} / \mathrm{m}^{2}$ for $2-3$ doses & $13 / 8$ & $6.0 \mathrm{mo}$ & $2 \mathrm{mo}$ \\
\hline \multirow[t]{2}{*}{ Amadori et al. (23) } & 56 & $78(62-86)$ & Untreated AML & Arm A: $3 \mathrm{mg} / \mathrm{m}^{2} \mathrm{D} 1,3$, and 5 & $21 / 0$ & NR & NR \\
\hline & & & & Arm B: $6 \mathrm{mg} / \mathrm{m}^{2} \mathrm{D} 1$ and 8 & $18 / 4$ & NR & NR \\
\hline Amadori et al. (24) & 40 & $76(61-89)$ & Untreated AML & $9 \mathrm{mg} / \mathrm{m}^{2} \mathrm{D} 1$ and $\mathrm{D} 15$ & $10 / 7$ & $6.1 \mathrm{mo}$ & $4 \mathrm{mo}$ \\
\hline Nabhan et al. (25) & 12 & $75(66-79)$ & Untreated AML & $9 \mathrm{mg} / \mathrm{m}^{2} \mathrm{D} 1$ and $\mathrm{D} 15$ & $27 / 0$ & NR & NR \\
\hline
\end{tabular}

Abbreviations: AML, Acute myeloid leukemia; CR, Compete remission; CRp, Complete remission with imcomplete platelet recovery; RFS, Relapse free survival; OS, Overall survival; NR, Not reported. 


\section{EFFICACY OF GO AS COMBINATION THERAPY FOR ADULT AML PATIENTS}

\subsection{Early Clinical Trials Demonstrating Beneficial Effects of GO}

Several trials have evaluated the efficacy of GO combined with chemotherapy as first-line therapy and for refractory/relapsed AML. Dose reduction of GO is required when used in combination with other cytotoxic agents due to its toxicity profile. In recent years, seven randomized phase III trials of newly diagnosed AML patients were performed (Table 2) [15-18,27-29]. In a United Kingdom Medical Research Council (MRC) AML15 trial, 1113 AML patients younger than 60 years of age without APL were randomly assigned to either receive or not receive GO as part of induction therapy [16]. The patients received a single dose of GO $\left(3 \mathrm{mg} / \mathrm{m}^{2}\right)$ on day 1 of the induction course as a component of three induction regimens consisting of daunorubicin and cytarabine (DA), cytarabine, daunorubicin and etoposide (ADE) or fludarabine, cytarabine, granulocyte colony-stimulating factor and idarubicin (FLAG-Ida). Subsequently, the patients not intended to undergo allogeneic HSCT were randomly assigned to receive GO combined with amsacrine, cytarabine and etoposide (MACE) or sole high-dose cytarabine. Although there were no differences in the overall response or survival rates among the two arms, there was a significant survival benefit for patients with favorable cytogenetics and a tendency toward a benefit for intermediate-risk patients. However, no benefits for patients in the poor-risk group were observed in the subgroup analyses based on cytogenetics [16].

\subsection{A Large-Scale Trial That Failed to Show Any Benefits of GO}

A second randomized multicenter phase III trial was conducted by the South West Oncology Group (SWOG) [15]. This study (SWOG S0106) randomly assigned 627 newly diagnosed patients younger than 60 years of age to receive induction therapy with DA with or without GO $\left(6 \mathrm{mg} / \mathrm{m}^{2}\right)$. Patients who achieved a CR received consolidation chemotherapy with three courses of high-dose cytarabine. Following the administration of consolidation therapy, a second round of randomization was performed to assign the patients to receive either three doses of GO $\left(5 \mathrm{mg} / \mathrm{m}^{2}\right.$ every 28 days) or no further treatment. An interim analysis demonstrated a CR rate of $74 \%$ in both arms, while no differences were observed in relapse-free survival (RFS), disease-free survival (DFS) or overall survival (OS). In addition, the incidence of fatal adverse events during induction therapy was significantly higher in the group that received GO compared with that observed in the control arm ( $5.8 \%$ vs $0.8 \%)$. This randomized study was stopped in early stage after the interim analysis, and GO was withdrawn from the US market in 2010.

Table 2. Gemtuzumab ozogamicin in combination with chemotherapy in relapsed and refracrory AML patients.

\begin{tabular}{|c|c|c|c|c|c|c|c|c|}
\hline \multirow{2}{*}{ Study (reference) } & \multirow{2}{*}{$\begin{array}{c}\text { Number } \\
\text { of } \\
\text { patients }\end{array}$} & \multirow{2}{*}{$\begin{array}{l}\text { Median } \\
\text { age } \\
\text { (range) }\end{array}$} & \multirow{2}{*}{ GO dose } & \multirow{2}{*}{$\begin{array}{l}\text { Combined } \\
\text { drug }\end{array}$} & $\mathrm{CR}$ & RFS/EFS/DFS & OS & $\begin{array}{l}\text { Induction } \\
\text { mortality }\end{array}$ \\
\hline & & & & & GO $(+)$ vs $(-)$ & $\mathrm{GO}(+)$ vs $(-)$ & $\mathrm{GO}(+)$ vs $(-)$ & GO $(+)$ vs $(-)$ \\
\hline \multicolumn{9}{|l|}{ Setting: induction therapy } \\
\hline SWOG SO106 (15) & 627 & $18-60$ & $6 \mathrm{mg} / \mathrm{m}^{2}$ & DA & $66 \%$ vs $69 \%$ & $\begin{array}{c}50 \% \text { vs } 49 \% \\
\text { at } 2 \mathrm{y} \text { RFS }\end{array}$ & $31 \mathrm{~m}$ vs $34 \mathrm{~m}$ & $5.8 \%$ vs $0.8 \%$ \\
\hline MRC AML15 （16） & 1113 & $\begin{array}{c}0-71 \\
(49)\end{array}$ & $3 \mathrm{mg} / \mathrm{m}^{2}$ & $\begin{array}{l}\text { DA, ADE, } \\
\text { FLAG-Ida }\end{array}$ & $82 \%$ vs $83 \%$ & $\begin{array}{c}39 \% \text { vs } 35 \% \\
\text { at } 5 y \text { RFS }\end{array}$ & $\begin{array}{l}42 \% \text { vs } 40 \% \\
\text { at } 5 y\end{array}$ & $7 \%$ vs $6 \%$ \\
\hline UK NCRI AML16 (17) & 1115 & $\begin{array}{l}51-84 \\
(67)\end{array}$ & $3 \mathrm{mg} / \mathrm{m}^{2}$ & DA, Dclo & $62 \%$ vs $58 \%$ & $\begin{array}{c}21 \% \text { vs } 16 \% \\
\text { at } 3 y \text { RFS }\end{array}$ & $\begin{array}{l}25 \% \text { vs } 20 \% \\
\text { at } 3 y\end{array}$ & $12 \%$ vs $11 \%$ \\
\hline ALFA-0701（18） & 280 & $\begin{array}{c}58-62 \\
(62)\end{array}$ & $\underset{5}{3 \mathrm{mg} / \mathrm{m}^{2} \times}$ & DA & $81 \%$ vs $75 \%$ & $\begin{array}{l}40.8 \% \text { vs } 17.1 \% \\
\text { at } 2 \mathrm{y} \text { EFS }\end{array}$ & $\begin{array}{c}53.2 \% \text { vs } 41.9 \% \\
\text { at } 2 \mathrm{y}\end{array}$ & $6.5 \%$ vs $4 \%$ \\
\hline $\begin{array}{l}\text { GOELAMS AML } 2006 \text { IR } \\
\text { (27) }\end{array}$ & 254 & $\begin{array}{l}18-60 \\
(50)\end{array}$ & $6 \mathrm{mg} / \mathrm{m}^{2}$ & DA & $92 \%$ vs $87 \%$ & $\begin{array}{l}51 \% \text { vs } 33 \% \\
\text { at } 3 y \text { EFS }\end{array}$ & $\begin{array}{l}53 \% \text { vs } 46 \% \\
\text { at } 3 y\end{array}$ & $4.2 \%$ vs $2.5 \%$ \\
\hline \multicolumn{9}{|l|}{ Setting: postremission therapy } \\
\hline ECOG E1900 (28) & 657 & $\begin{array}{l}18-60 \\
(47)\end{array}$ & \multicolumn{2}{|c|}{$\begin{array}{c}6 \mathrm{mg} / \mathrm{m}^{2}+\mathrm{ASCT} \text { vs } \\
\text { HD-AraC }\end{array}$} & - & $\begin{array}{c}33.6 \% \text { vs } 35.9 \% \\
\text { at } 4 y \text { DFS }\end{array}$ & $\begin{array}{c}40.8 \% \text { vs } 41.9 \% \\
\text { at } 4 y\end{array}$ & - \\
\hline HOVON-43 (29) & 232 & $\begin{array}{c}60-78 \\
(66)\end{array}$ & $6 \underset{3}{\mathrm{mg} / \mathrm{m}^{2} \times}$ & - & - & $\begin{array}{l}17 \% \text { vs } 16 \% \\
\text { at } 5 y \text { DFS }\end{array}$ & $\begin{array}{c}28 \% \text { vs } 21 \% \text { at } \\
5 y\end{array}$ & - \\
\hline
\end{tabular}

Abbreviations: GO, Gemtuzumab ozogamicin; CR, Complete remission; RFS, Rrelapse free survival; EFS, Event free survival; DFS, Disease free survival; OS, Overall survival; DA, Daunorubicin/Cytarabine; ADE, Cytarabine/Daunorubicin/Etoposide; FLAG-Ida, Fludarabine/Cytarabine/Granulocyte colony-stimulating factor/Idarubicin; Dclo, Daunorubicin/Cllofarabine. 


\subsection{Clinical Trials Demonstrating Beneficial Effects of GO in Recent Years}

More recently, the results of the United Kingdom National Cancer Research Institute (UK NCRI) AML16 trial were published in 2012. This study randomly assigned 1115 elderly patients (median age: 67 years) to receive daunorubicin and either clofarabine or cytarabine with or without GO $\left(3 \mathrm{mg} / \mathrm{m}^{2}\right)$ [17]. There were no differences in the $\mathrm{CR}$ rate; however, the 3-year cumulative incidence of relapse was significantly lower (GO vs no GO: CIR at 3 years $68 \%$ vs $76 \%$; $=0.007$ ) and the 3 -year survival rate was significantly higher in the GO arm (3 year OS $25 \%$ vs $20 \%$; $p=0.05$ ). The addition of GO did not increase the mortality rate during the administration of induction chemotherapy. A meta-analysis of 2, 228 patients included in the MRC AML 15 and UK NCRI AML 16 trials also showed significant improvements in the relapse and OS rates in the GO arm (3 $\mathrm{mg} / \mathrm{m}^{2} \mathrm{GO}$ ) [17].

The Acute Leukemia French Association (ALFA) investigated whether the addition of low fractionated-dose GO to standard front-line chemotherapy improves eventfree survival (EFS) as the primary end point [18]. In the phase 3 ALFA-0701 study, 280 patients between 50 to 70 years of age were randomly assigned to receive DA with or without $\mathrm{GO}\left(3 \mathrm{mg} / \mathrm{m}^{2}\right.$ on days 1,4 and 7 during induction and day 1 of each of the two consolidation chemotherapies). The $\mathrm{CR}$ rate during induction did not differ between the arms; however, the EFS, OS and RFS were significantly improved in the GO group without an increase in the risk of death from toxicity. At the time point of two years, the EFS was estimated to be $17.1 \%$ in the control group versus $40.8 \%$ in the GO group $(\mathrm{p}=$ 0.0003 ), while the OS was $41.9 \%$ versus $53.2 \%(\mathrm{p}=$ 0.0368 ) and the RFS was $22.7 \%$ versus $50.3 \%$, respectively $(p=0.0003)$. The results of the cytogenetic and genotypic analyses demonstrated a survival benefit among the patients with favorable or intermediate cytogenetics compared to that observed in the patients with unfavorable cytogenetics and a survival benefit among the patients positive for the FLT3-internal tandem duplication (ITD) mutation compared to that observed in the patients negative for this mutation [18]. Among the patients with the NPM1 mutation and a WT-1 expression, more patients in whom the levels of the transcripts decreased below the detection limits at postinduction were found in the GO arm compared to the control arm. Furthermore, the detectable NPM1 and WT-1 transcript levels at postinduction in non-GO arm were associated with a higher relapse rate [30].

In a Groupe Ouest-Est des Leucémies et des Autres Maladies du Sang (GOELAMS) AML 2006 IR study, 254 patients ranging from 18 to 60 years of age with de novo AML were randomly assigned to receive DA with or without GO $\left(6 \mathrm{mg} / \mathrm{m}^{2}\right.$ for induction and first consolidation chemotherapy) [27]. In the subset of patients with intermediate cytogenetics who were unable to receive subsequent allogeneic HST, the EFS was significantly higher in the GO group (GO vs no GO: $53.7 \%$ vs $27 \%$; $p$ $=0.0308$ ), while there were no differences regarding OS. These trials demonstrated that the addition of a low dose of GO to cytarabine and anthracycline-based induction and consolidation chemotherapy improves survival, but not CR rates, without increasing GO toxicity in AML patients with more favorable cytogenetics.

\subsection{Beneficial Effects of GO Have Not Been Demonstrated in Postremission Therapy}

The Eastern Cooperative Oncology Group (ECOG) and the Dutch-Belgian Hemato-Oncology Cooperative Group (HOVON) evaluated the efficacy of GO as postremission therapy. In the ECOG trial E1900, patients with favorable and intermediate cytogenetics received postremission therapy with two courses of high-dose cytarabine followed by GO $\left(6 \mathrm{mg} / \mathrm{m}^{2}\right)$ and autologous HST or autologous HST alone [28]. There were no differences in DFS (GO vs no GO: DFS at 4 years $33.6 \%$ vs $35.9 \%$; $p=$ $0.54)$ or OS $(41.3 \%$ vs $41.9 \%$; $=0.52)$ between the arms. In the HOVON-43 study, elderly patients with AML in a first $\mathrm{CR}$ following intensive induction chemotherapy were randomized to receive three cycles of GO $\left(6 \mathrm{mg} / \mathrm{m}^{2}\right.$ every four weeks) or no postremission therapy [29]. There were no significant differences between the treatment groups in OS or DFS (GO vs no GO: DFS at 5 years $17 \%$ vs $16 \%$ ). Therefore, these trials demonstrated that GO does not exhibit beneficial effects in postremission therapy.

\subsection{GO Combined with Chemotherapy Is Effective for Relapsed AML}

A number of GO-containing combination chemotherapies for relapsed and refractory AML have been reported (Table 3) [31-42]. The response rates observed in these studies range from $12 \%$ to $68 \%$ and appear to increase as time progresses. The toxicity profile is variable from study to study, particularly with respect to liver toxicity. In a dose escalation trial of relapsed and refractory AML, which was conducted by the Cancer and Leukemia Group B (CALGB), a combined regimen with GO (9 $\mathrm{mg} / \mathrm{m}^{2}$ ) and high-dose cytarabine (HiDAC) was safely administered, resulting in a CR rate of $32 \%$ [40]. In an encouraging phase II study, GO combined with intermediate-dose cytarabine and mitoxantrone (MIDAM) produced a complete remission rate as high as $63 \%$ and an overall survival (OS) of 9.5 months in patients with pri- 
Table 3. GO in combination chemotherapy in relapsed and/or refractory acute myelid leukemia patients.

\begin{tabular}{|c|c|c|c|c|c|c|}
\hline Reference & $\begin{array}{l}\text { Number of } \\
\text { Patients }\end{array}$ & $\begin{array}{l}\text { Median age } \\
\text { (range) }\end{array}$ & GO dosage & Additional agents & $\begin{array}{c}\mathrm{CR} / \mathrm{CR} \\
\mathrm{p}(\%)\end{array}$ & $\begin{array}{l}\text { Incidence of } \\
\text { VOD (\%) }\end{array}$ \\
\hline Cortes et al. (31) & 17 & $55(20-70)$ & $9 \mathrm{mg} / \mathrm{m}^{2} \mathrm{D} 1$ & Ara-C, Topotecan & 12 & 5.9 \\
\hline Alvarado et al. (32) & 14 & $61(34-74)$ & $6 \mathrm{mg} / \mathrm{m}^{2} \mathrm{D} 1,15$ & Ara-C, Idarubicin & $21 / 21$ & 14.3 \\
\hline Tsimberidou et al. (33) & 32 & $53(18-78)$ & $4.5 \mathrm{mg} / \mathrm{m}^{2} \mathrm{D} 1$ & Ara-C, Fludarabine, CSA & $28 / 6$ & 9.4 \\
\hline Specchia et al. (34) & 21 & $52(36-68)$ & $3 \mathrm{mg} / \mathrm{m}^{2} \mathrm{D} 1,14$ & Ara-C, Mitoxantrone & $9 / 9$ & 0 \\
\hline Chevallier et al. (35) & 62 & $55.5(16-71)$ & $9 \mathrm{mg} / \mathrm{m}^{2} \mathrm{D} 4$ & Ara-C, Mitoxantrone & $50 / 13$ & 3 \\
\hline Schlenk et al. (36) & 94 & $48(22-62)$ & $3 \mathrm{mg} / \mathrm{m}^{2} \mathrm{D} 1$ & Ara-C, Mitoxantrone, ATRA & $30 / 20$ & 9 \\
\hline Fianchi et al. (37) & 53 & $69(65-77)$ & $6 \mathrm{mg} / \mathrm{m}^{2} \mathrm{D} 9$ & Ara-C, G-CSF & $43 / 2$ & 2 \\
\hline Martin et al. (38) & 48 & $47(20-68)$ & $9 \mathrm{mg} / \mathrm{m}^{2} \mathrm{D} 8$ & Ara-C, Fludarabine, Idarubicin & $29 / 27$ & 15 \\
\hline Litzow et al. (39) & 26 & $60(27-75)$ & $6 \mathrm{mg} / \mathrm{m}^{2} \mathrm{D} 5$ & Ara-C & 12 & NR \\
\hline Stone et al. (40) & 37 & $64(55-70)$ & $9 \mathrm{mg} / \mathrm{m}^{2} \mathrm{D} 7$ & Ara-C & 32 & NR \\
\hline Prebet et al. (41) & 34 & $51(24-71)$ & $3-9 \mathrm{mg} / \mathrm{m}^{2}$ & $\begin{array}{c}\text { Ara-C } \pm \text { Mitoxantrone, Etoposide, } \\
\text { Irinotecan }\end{array}$ & 68 & 6 \\
\hline Farhat et al. (42) & 20 & $60(50-70)$ & $3 \mathrm{mg} / \mathrm{m}^{2} \mathrm{D} 1,4,7$ & Ara-C, Daunorubicin & $55 / 10$ & 0 \\
\hline
\end{tabular}

Abbreviations: GO, Gemtuzumab ozogamicin; CR, Compete remission; CRp, Complete remission with imcomplete platelet recovery; VOD, Veno occlusive disease.

mary refractory and relapsed AML [35]. A meta-analysis revealed patients with mutated NPM1, but not concurrent FLT3-ITD, to show a favorable overall response (OR) rate of $85 \%$ and a 5-year survival rate of $80 \%$ [43]. The German Austrian AML study Group (AMLSG) 04 - 05 trial evaluated the efficacy of high-dose cytarabine, mitoxantrone and all-trans retinoic acid (ATRA) in combination with GO (GO-A-HAM) in younger adult patients with primary refractory AML [36]. The CR rate was 50\% and $12 \%$ of the patients achieved a partial remission (PR). The incidence of VOD following allogeneic HSCT within three months after GO-A-HAM was $9 \%$ without differences when compared with historical controls. The patients with adverse cytogenetics and/or FLT3-ITD exhibited a significantly inferior OS of $38 \%$ after one year of follow-up compared to the $81 \%$ observed in the remaining patients. However, the OS of the patients who received allogeneic HSCT was similar between the groups [36]. More recently, the outcomes of combined regimens with intermediate to high-dose cytarabine (IHDAraC) and IHDAraC with GO (3-9 mg/m $\mathrm{m}^{2}$, average $\left.6 \mathrm{mg} / \mathrm{m}^{2}\right)$ were retrospectively compared in patients with a first relapse of AML [41]. The OR rate (GO vs no GO: $68 \%$ vs $45 \%$; p $=0.04)$, EFS (24 months vs 6 months; $p=0.002)$ and OS (median, 35 months vs 6 months; $\mathrm{p}=0.001$ ) were significantly higher in the GO group. These effects, however, were restricted to patients with low-risk and intermediate-risk cytogenetics. In the treatment of elderly pa- tients with refractory or relapsed AML, GO combined with cytarabine and G-CSF, but not anthracycline (GAraMy regimen), was acceptable in terms of both myeloid and non-myeloid toxicities. The OR rate was 57\% and the median OS was nine months [37].

\subsection{GO Fails to Exhibit Efficacy in Some Combination Regimens for Relapsed AML}

In contrast to these favorable results, a retrospective study showed that the addition of GO to fludarabine, cytarabine, G-CSF and idarubicin (FLAG-Ida) failed to improve the response rate, duration of response or OS compared with FLAG-Ida alone [38]. The ECOG conducted a randomized phase II study of patients with primary refractory and relapsed AML [39]. These patients were randomly assigned to receive intermediate-dose cytarabine with GO $\left(6 \mathrm{mg} / \mathrm{m}^{2}\right)$ (Arm A), intermediate-dose cytarabine with liposomal daunorubicin (Arm B) or intermediate-dose cytarabine with cyclophosphamide and topotecan (Arm C). The $\mathrm{CR} / \mathrm{CRp}$ rate was as low as $12 \%$ in Arm A, 7\% in Arm B and 4\% in Arm C. The median OS for all treatment arms was 3.4 months without significant differences between the groups [39]. In a non-randomized phase II study in which two combination regimens with fludarabine, cytarabine and idarubicin with or without GO $\left(9 \mathrm{mg} / \mathrm{m}^{2}\right)$ (FLAG-IM and FLAG-I) were compared without demonstrating any beneficial effects of 
$\mathrm{GO}$, the addition of GO failed to improve the OR rate (GO vs non-GO: $56 \%$ vs $52 \%$ ) or overall survival time (5.0 months vs 8.8 months) in patients with relapsed or refractory AML [38]. Currently, several studies are investigating the efficacy of GO-containing combination regimens with vorinostat [44], azacitidine [45] and decitabine [46].

\section{GO IS A POTENT ANTILEUKEMIC AGENT AGAINST ACUTE PROMYELOCYTIC LEUKEMIA (APL)}

GO exhibits a significant and potent activity against both newly diagnosed and recurrent APL. This efficacy results from a high surface expression of CD33 and low expression levels of P-glycoprotein in APL cells [47-49]. LoCoco et al. reported the efficacy of GO as monotherapy $\left(6 \mathrm{mg} / \mathrm{m}^{2}\right.$ on days 1 and 15) for molecular relapsed APL [50]. In this study, patients who achieved molecular remission subsequently received additional GO treatment. Eighty-eight percent of the patients obtained a molecular response and $44 \%$ of the responders remained in sustained molecular remission. Ravandi et al. investigated the outcomes of a combined regimen with ATRA and arsenic trioxide (ATO) with or without GO in newly diagnosed patients with APL [51]. GO was given to highrisk patients with a presenting leukocyte count over $10,000 / \mathrm{L}$ and was further added if the leukocyte count increased above 30,000/L during induction chemotherapy. The OR rate with GO was $92 \%$ after induction and the molecular remission rate was $94 \%$ three months after the completion of three rounds of consolidation with ATRA and ATO with favorable outcomes and fewer complications compared with historical controls. Aribi et al. showed similar results among eight patients with APL in a first recurrence who were treated with ATRA, ATO and GO [52]. All patients had previously received ATRA as a single agent or in combination with other chemotherapies. All patients achieved a molecular CR, and six of the eight patients were alive and had remained in remission after a median follow-up of 36 months. Based on the results of these studies, GO is indicated in many aspects of APL.

\section{CONCLUSION}

GO is a CD33-molecular targeting agent for use in the treatment of AML and is effective depending on the aspects and status of AML and the combination of some chemotherapeutic agents. The toxicity profile of GO is acceptable in all ages, and dose reduction of GO appears to reduce the incidence of liver toxicity, particularly SOS. From this point of view, the use of GO treatment is an attractive therapeutic approach. Therefore, the reappearance of GO in the treatment of AML is expected world- wide. Further investigations regarding the optimized use of GO should be conducted.

\section{REFERENCES}

[1] Lowenberg, B., Downing, J.R. and Burnett, A. (1999) Acute myeloid leukemia. New England Journal of Medicine, 341, 1051-1062. doi:10.1056/NEJM199909303411407

[2] Brincker, H. (1985) Estimate of overall treatment results in acute nonlymphocytic leukemia based on age-specific rates of incidence and of complete remission. Cancer Treatment Report, 69, 5-11.

[3] Burnett, A.K., Hills, R.K., Milligan, D.W., Goldstone, A.H., Prentice, A.G., McMullin, M.F., Duncombe, A., Gibson, B. and Wheatley, K. (2011) Attempts to optimize induction and consolidation treatment in acute myeloid leukemia: Results of the MRC AML12 trial. Journal of Clinical Oncology, 28, 586-595. doi:10.1200/JCO.2009.22.9088

[4] Fernandez, H.F., Sun, Z., Yao, X., Litzow, M.R., Luger, S.M., Paietta, E.M., Racevskis, J., Dewald, G.W., Ketterling, R.P., Bennett, J.M., Rowe, J.M., Lazarus, H.M. and Tallman, M.S. (2009) Anthracycline dose intensification in acute myeloid leukemia. New England Journal of Medicine, 361, 1249-1259. doi:10.1056/NEJMoa0904544

[5] Mandelli, F., Vignetti, M., Suciu, S., Stasi, R., Petti, M.C., Meloni, G., Muus, P., Marmont, F., Marie, J.P., Labar, B., Thomas, X., Di Raimondo, F., Willemze, R., Liso, V., Ferrara, F., Baila, L., Fazi, P., Zittoun, R., Amadori, S. and de Witte, T. (2009) Daunorubicin versus mitoxantrone versus idarubicin as induction and consolidation chemotherapy for adults with acute myeloid leukemia: The EORTC and GIMEMA Groups Study AML-10. Journal of Clinical Oncology, 27, 5397-5403. doi:10.1200/JCO.2008.20.6490

[6] Goldstone, A.H., Burnett, A.K., Wheatley, K., Smith, A.G., Hutchinson, R.M. and Clark, R.E. (2001) Attempts to improve treatment outcomes in acute myeloid leukemia (AML) in older patients: the results of the United Kingdom Medical Research Council AML11 trial. Blood, 98, 1302-1311. doi:10.1182/blood.V98.5.1302

[7] Burnett, A.K., Hills, R.K., Green, C., Jenkinson, S., Koo, K., Patel, Y., Guy, C., Gilkes, A., Milligan, D.W., Goldstone, A.H., Prentice, A.G., Wheatley, K., Linch, D.C. and Gale, R.E. (2010) The impact on outcome of the addition of alltrans retinoic acid to intensive chemotherapy in younger patients with nonacute promyelocytic acute myeloid leukemia: Overall results and results in genotypic subgroups defined by mutations in NPM1, FLT3, and CEBPA. Blood, 115, 948-956. doi:10.1182/blood-2009-08-236588

[8] Buchner, T., Berdel, W.E., Haferlach, C., Haferlach, T., Schnittger, S., Muller-Tidow, C., Braess, J., Spiekermann, K., Kienast, J., Staib, P., Grüneisen, A., Kern, W., Reichle, A., Maschmeyer, G., Aul, C., Lengfelder, E., Sauerland, M.C., Heinecke, A., Wörmann, B. and Hiddemann, W. (2009) Age-related risk profile and chemotherapy dose response in acute myeloid leukemia: A study by the German Acute Myeloid Leukemia Cooperative Group. Journal of Clini- 
cal Oncology, 27, 61-69. doi:10.1200/JCO.2007.15.4245

[9] Hamann, P.R., Hinman, L.M., Hollander, I., Beyer, C.F., Lindh, D., Holcomb, R., Hallett, W., Tsou, H.R., Upeslacis, J., Shochat, D., Mountain, A., Flowers, D.A. and Bernstein, I. (2002) Gemtuzumab ozogamicin, a potent and selective anti-CD33 antibody-calicheamicin conjugate for treatment of acute myeloid leukemia. Bioconjugate Chemistry, 13, 47-58. doi:10.1021/bc010021y

[10] Dinndorf, P.A., Andrews, R.G., Benjamin, D., Ridgway, D., Wolff, L. and Bernstein, I.D. (1986) Expression of normal myeloid-associated antigens by acute leukemia cells. Blood, 67, 1048-1053.

[11] Ikemoto, N., Kumar, R.A., Ling, T.T., Ellestad, G.A., Danishefsky, S.J. and Patel, D.J. (1995) Calicheamicin-DNA complexes: Warhead alignment and saccharide recognition of the minor groove. Proceedings of the National Academy of Sciences of the USA, 92, 10506-10510. doi:10.1073/pnas.92.23.10506

[12] Sievers, E.L., Larson, R.A., Stadtmauer, E.A., Estey, E., Lowenberg, B., Dombret, H., Karanes, C., Theobald, M., Bennett, J.M., Sherman, M.L., et al. (2001) Efficacy and safety of gemtuzumab ozogamicin in patients with CD33positive acute myeloid leukemia in first relapse. Journal of Clinical Oncology, 19, 3244-3254.

[13] Larson, R.A., Sievers, E.L., Stadtmauer, E.A., Lowenberg, B., Estey, E.H., Dombret, H., Theobald, M., Voliotis, D., Bennett, J.M., Richie, M., et al. (2005) Final report of the efficacy and safety of gemtuzumab ozogamicin (Mylotarg) in patients with CD33-positive acute myeloid leukemia in first recurrence. Cancer, 104, 1442-1452. doi:10.1002/cncr.21326

[14] Kobayashi, Y., Tobinai, K., Takeshita, A., Naito, K., Asai, O., Dobashi, N., Furusawa, S., Saito, K., Mitani, K., Morishima, Y., et al. (2009) Phase I/II study of humanized anti-CD33 antibody conjugated with calicheamicin, gemtuzumab ozogamicin, in relapsed or refractory acute myeloid leukemia: final results of Japanese multicenter cooperative study. International Journal of Hematology, 89, 460-469. doi:10.1007/s12185-009-0298-1

[15] Petersdorf, S., Kopecky, K., Stuart, R.K., Larson, R.A., Nevill, T.J., Stenke, L., Slovak, M.L., Tallman, M.S., Willman, C.L., Erba, H. and Appelbaum, F.R. (2009) Preliminary results of Southwest Oncology Group Study S0106: An international intergroup phase 3 randomized trial comparing the addition of gemtuzumab ozogamicin to standard induction therapy versus standard induction therapy followed by a second randomization to post-consolidation gemtuzumab ozogamicin versus no additional therapy for previously untreated acute myeloid leukemia. Blood, 114, (abstr 790).

[16] Burnett, A.K., Hills, R.K., Milligan, D., Kjeldsen, L., Kell, J., Russell, N.H., Yin, J.A., Hunter, A., Goldstone, A.H. and Wheatley, K. (2011) Identification of patients with acute myeloblastic leukemia who benefit from the addition of gemtuzumab ozogamicin: Results of the MRC AML15 trial. Journal of Clinical Oncology, 29, 369-377. doi:10.1200/JCO.2010.31.4310

[17] Burnett, A.K., Russell, N.H., Hills, R.K., Kell, J., Freeman, S., Kjeldsen, L., Hunter, A.E., Yin, J., Craddock,
C.F., Dufva, I.H., Wheatley, K. and Miligan, D. (2012) Addition of gemtuzumab ozogamicin to induction chemotherapy improves survival in older patients with acute myeloid leukemia. Journal of Clinical Oncology, 30, 3924-3931. doi:10.1200/JCO.2012.42.2964

[18] Castaigne, S., Pautas, C., Terre, C., Raffoux, E., Bordessoule, D., Bastie, J.N., Legrand, O., Thomas, X., Turlure, P., Reman, O., de Revel, T., Gastaud, L., de Gunzburg, N., Contentin, N., Henry, E., Marolleau, J.P., Aljijakli, A., Rousselot, P., Fenaux, P., Preudhomme, C., Chevret, S., Dombret, H. and Acute Leukemia French Association. (2012) Effect of gemtuzumab ozogamicin on survival of adult patients with de-novo acute myeloid leukaemia (ALFA-0701): A randomised, open-label, phase 3 study. Lancet, 379, 1508-1516. doi:10.1016/S0140-6736(12)60485-1

[19] Sievers, E.L., Appelbaum, F.R., Spielberger, R.T., Forman, S.J., Flowers, D., Smith, F.O., Shannon-Dorcy, K., Berger, M.S. and Bernstein, I.D. (1999) Selective ablation of acute myeloid leukemia using antibody-targeted chemotherapy: A phase I study of an anti-CD33 calicheamicin immunoconjugate. Blood, 93, 3678-3684.

[20] Bross, P.F., Beitz, J., Chen, G., Chen, X.H., Duffy, E., Kieffer, L., Roy, S., Sridhara, R., Rahman, A., Williams, G. and Pazdur, R. (2001) Approval summary: Gemtuzumab ozogamicin in relapsed acute myeloid leukemia. Clinical Cancer Research, 7, 1490-1496.

[21] Taksin, A.L., Legrand, O., Raffoux, E., de Revel, T., Thomas, X., Contentin, N., Bouabdallah, R., Pautas, C., Turlure, P., Reman, O., Gardin, C., Varet, B., de Botton, S., Pousset, F., Farhat, H., Chevret, S., Dombret, H. and Castaigne, S. (2007) High efficacy and safety profile of fractionated doses of Mylotarg as induction therapy in patients with relapsed acute myeloblastic leukemia: A prospective study of the alfa group. Leukemia, 21, 66-71. doi:10.1038/sj.leu.2404434

[22] Piccaluga, P.P., Martinelli, G., Rondoni, M., Malagola, M., Gaitani, S., Isidori, A., Bonini, A., Gugliotta, L., Luppi, M., Morselli, M., Sparaventi, G., Visani, G. and Baccarani, M. (2004) Gemtuzumab ozogamicin for relapsed and refractory acute myeloid leukemia and myeloid sarcomas. Leuk Lymphoma, 45, 1791-1795. doi:10.1080/1042819042000219485

[23] Amadori, S., Suciu, S., Selleslag, D., Stasi, R., Alimena, G., Baila, L., Rizzoli, V., Borlenghi, E., Gaidano, G., Magro, D., Torelli, G., Muus, P., Venditti, A., Cacciola, E., Lauria, F., Vignetti, M. and de Witte, T. (2010) Randomized trial of two schedules of low-dose gemtuzumab ozogamicin as induction monotherapy for newly diagnosed acute myeloid leukaemia in older patients not considered candidates for intensive chemotherapy. A phase II study of the EORTC and GIMEMA leukaemia groups (AML-19). British Journal of Haematology, 149, 376-382. doi:10.1111/j.1365-2141.2010.08095.x

[24] Amadori, S., Suciu, S., Stasi, R., Willemze, R., Mandelli, F., Selleslag, D., Denzlinger, C., Muus, P., Stauder, R., Berneman, Z., Pruijt, J., Nobile, F., Cassibba, V., Marie, J.P., Beel-dens, F., Baila, L., Vignetti, M. and de Witte, T. (2005) Gemtuzumab ozogamicin (Mylotarg) as single-agent treatment for frail patients 61 years of age and older with 
acute myeloid leukemia: final results of AML-15B, a phase 2 study of the European Organisation for Research and Treatment of Cancer and Gruppo Italiano Malattie Ematologiche dell'Adulto Leukemia Groups. Leukemia, 19, 1768-1773. doi:10.1038/sj.leu.2403901

[25] Nabhan, C., Rundhaugen, L.M., Riley, M.B., Rademaker, A., Boehlke, L., Jatoi, M. and Tallman, M.S. (2005) Phase II pilot trial of gemtuzumab ozogamicin (GO) as first line therapy in acute myeloid leukemia patients age 65 or older. Leukemia Research, 29, 53-57. doi:10.1016/j.leukres.2004.04.011

[26] Rajvanshi, P., Shulman, H.M., Sievers, E.L. and McDonald, G.B. (2002) Hepatic sinusoidal obstruction after gemtuzumab ozogamicin (Mylotarg) therapy. Blood, 99, 23102314. doi:10.1182/blood.V99.7.2310

[27] Delaunay, J., Recher, C., Pigneux, A., Witz, F., Vey, N., Blanchet, O., Lefebvre, P., Luquet, I., Guillerme, I., Volteau, C., Gyan, E., Lioure, B., Jourdan, E., Bouscary, D., Guieze, R., Randriamalala, E., Uribe, M.E.O., Dreyfus, F., Lacombe, C., Béné, Mc., Cahn, J.Y., Harousseau, J.C. and Ifrah, N. (2011) Addition of gemtuzumab ozogamycin to chemotherapy improves event-free survival but not overall survival of AML patients with intermediate cytogenetics not eligible for allogeneic transplantation. Results of the GOELAMS AML 2006 IR study. Blood, 118, 79.

[28] Fernandez, H.F., Sun, Z., Litzow, M.R., Luger, S.M., Paietta, E.M., Racevskis, J., Dewald, G., Ketterling, R.P., Rowe, J.M., Lazarus, H.M. and Tallman, M.S. (2011) Autologous transplantation gives encouraging results for young adults with favorable-risk acute myeloid leukemia, but is not improved with gemtuzumab ozogamicin. Blood, 117, 5306-5613. doi:10.1182/blood-2010-09-309229

[29] Lowenberg, B., Beck, J., Graux, C., van Putten, W., Schouten, H.C., Verdonck, L.F., Ferrant, A., Sonneveld, P., Jongen-Lavrencic, M., von Lilienfeld-Toal, M., Biemond, B.J., Vellenga, E., Breems, D., de Muijnck, H., Schaafsma, R., Verhoef, G., Döhner, H., Gratwohl, A., Pabst, T., Ossenkoppele, G.J., Maertens, J., Dutch-Belgian HematoOncology Cooperative Group (HOVON), German Austrian AML Study Group (AMLSG) and Swiss Group for Clinical Cancer Research Collaborative Group (SAKK). (2010) Gemtuzumab ozogamicin as postremission treatment in AML at 60 years of age or more: results of a multicenter phase 3 study. Blood, 115, 2586-2591. doi:10.1182/blood-2009-10-246470

[30] Lambert, J., Jerome Lambert, J., Olivier Nibourel, O., Pautas, C., Hayette, S., Cayuela, J.M., Terre, C., Rousselot, P., Dombret, H., Preudhomme, C., Castaigne, S. and Renneville, A. (2012) Minimal residual disease assessed by WT1 expression and NPM1 mutations specific RQ-PCR assays identifies patients with distinct outcomes in the ALFA 0701 trial and is decreased by treatment with Gemtuzumab Ozogamicin. Blood, 120, 659.

[31] Cortes, J., Tsimberidou, A.M., Alvarez, R., Thomas, D., Beran, M., Kantarjian, H., Estey, E. and Giles, F.J. (2002) Mylotarg combined with topotecan and cytarabine in patients with refractory acute myelogenous leukemia. Cancer Chemotherapy Pharmacology, 50, 497-500. doi:10.1007/s00280-002-0539-y

[32] Alvarado, Y., Tsimberidou, A., Kantarjian, H., Cortes, J.,
Garcia-Manero, G., Faderl, S., Thomas, D., Estey, E. and Giles, F.J. (2003) Pilot study of mylotarg, idarubicin and cytarabine combination regimen in patients with primary resistant or relapsed acute myeloid leukemia. Cancer Chemotherapy Pharmacology, 51, 87-90. doi:10.1007/s00280-002-0546-Z

[33] Tsimberidou, A., Cortes, J., Thomas, D., Garcia-Manero, G., Verstovsek, S., Faderl, S., Albitar, M., Kantarjian, H., Estey, E. and Giles, F.J. (2003) Gemtuzumab ozogamicin, fludarabine, cytarabine and cyclosporine combination regimen in patients with CD33+ primary resistant or relapsed acute myeloid leukemia. Leukemia Research, 27, 893-897. doi:10.1016/S0145-2126(03)00022-5

[34] Specchia, G., Pastore, D., Carluccio, P., Spinosa, G., Giannoccaro, M., Rizzi, R., Mestice, A. and Liso, V. (2007) Gemtuzumab ozogamicin with cytarabine and mitoxantrone as a third-line treatment in a poor prognosis group of adult acute myeloid leukemia patients: A single-center experience. Annals of Hematology, 86, 425-428. doi:10.1007/s00277-007-0272-z

[35] Chevallier, P., Delaunay, J., Turlure, P., Pigneux, A., Hunault, M., Garand, R., Guillaume, T., Avet-Loiseau, H., Dmytruk, N., Girault, S., Milpied, N., Ifrah, N., Mohty, M. and Harousseau, J.L. (2008) Long-term disease-free survival after gemtuzumab, intermediate-dose cytarabine, and mitoxantrone in patients with $\mathrm{CD} 33(+)$ primary resistant or relapsed acute myeloid leukemia. Journal of Clinical Oncology, 26, 5192-5197. doi:10.1200/JCO.2007.15.9764

[36] Schlenk, R.F., Dohner, K., Jürgen Krauter, J., Späth, D., Valle, F., Heydrich, B., Horst, H.A., Schmidt-Wolf, I., Rummel, A., Götze, K., Koller, E., Petzer, A., Mergenthaler, H.G., Salwender, H., Fiedler, W., Kirchen, H., Haase, D., Krämers, S., Theobald, A., Matzdorff, A.C., Ganser, A., Döhner, H. (2007) All-Trans retinoic acid and gemtuzumab ozogamicin as adjunct to high-Dose cytarabine-Based salvage therapy in primary refractory acute myeloid leukemia: Results of AMLSG 05-04 trial. Blood, 110.

[37] Fianchi, L., Pagano, L., Leoni, F., Storti, S., Voso, M.T., Valentini, C.G., Rutella, S., Scardocci, A., Caira, M., Gianfaldoni, G. and Leone, G. (2008) Gemtuzumab ozogamicin, cytosine arabinoside, G-CSF combination (GAraMy) in the treatment of elderly patients with poorprognosis acute myeloid leukemia. Annals of Oncology, 19, 128-134. doi:10.1093/annonc/mdm451

[38] Martin, M.G., Augustin, K.M., Uy, G.L., Welch, J.S., Hladnik, L., Goyal, S., Tiwari, D., Monahan, R.S., Reichley, R.M., Cashen, A.F., Stockerl-Goldstein, K., Westervelt, P., Abboud, C.N., Dipersio, J.F. and Vij, R. (2009) Alvage therapy for acute myeloid leukemia with fludarabine, cytarabine, and idarubicin with or without gemtuzumab ozogamicin and with concurrent or sequential GCSF. American Journal of Hematology, 84, 733-737. doi:10.1002/ajh.21545

[39] Ritzow, M.R., Othus, M., Cripe, L.D., Gore, S.D., Lazarus, H.M., Lee, S.J., Bennett, J.M., Paietta, E.M., Dewald, G.W., Rowe, J.M. and Tallman, M.S. (2010) Failure of three novel regimens to improve outcome for patients with relapsed or refractory acute myeloid leukaemia: A 
report from the Eastern Cooperative Oncology Group. British Journal of Haematology, 148, 217-225. doi:10.1111/j.1365-2141.2009.07917.x

[40] Stone, R.M., Moser, B., Sanford, B., Schulman, P., Kolitz, J.E., Allen, S., Stock, W., Galinsky, I., Vij, R., Marcucci, G., Hurd, D. and Larson, R.A. (2011) High dose cytarabine plus gemtuzumab ozogamicin for patients with relapsed or refractory acute myeloid leukemia: Cancer and Leukemia Group B study 19902. Leukemia Research, 35, 329-333. doi:10.1016/j.leukres.2010.07.017

[41] Prebet, T., Etienne, A., Devillier, R., Romeo, E., Charbonnier, A., D'Incan, E., Esterni, B., Arnoulet, C., Blaise, D. and Vey, N. (2011) Improved outcome of patients with low- and intermediate-risk cytogenetics acute myeloid leukemia (AML) in first relapse with gemtuzumab and cytarabine versus cytarabine: Results of a retrospective comparative study. Cancer, 117, 974-981. doi:10.1002/cncr.25554

[42] Farhat, H., Reman, O., Raffoux, E., Berthon, C., Pautas, C., Kammoun, L., Chantepie, S., Gardin, C., Rousselot, P., Chevret, S., Dombret, H. and Castaigne, S. (2012) Fractionated doses of gemtuzumab ozogamicin with escalated doses of daunorubicin and cytarabine as first acute myeloid leukemia salvage in patients aged 50 - 70-year old: A phase $1 / 2$ study of the acute leukemia French association. American Journal of Hematology, 87, 62-65. doi:10.1002/ajh.22201

[43] Chevallier, P., Prebet, T., Pigneux, A., Hunault, M., Delaunay, J., Perry, F., Lode, L., Richebourg, S., Blanchet, O., Vey, N., Ifrah, N., Milpied, N., Blaise, D., Harousseau, J.L. and Mohty, M. (2010) Influence of NPM1 and FLT3ITD status on outcome in relapsed/refractory AML patients receiving salvage therapy including gemtuzumab ozogamicin. Leukemia, 24, 467-469. doi:10.1038/leu.2009.214

[44] Walter, R.B., Medeiros, B.C., Powell, B.L., Schiffer, C.A., Appelbaum, F.R. and Estey, E.H. (2012) Phase II trial of vorinostat and gemtuzumab ozogamicin as induction and post-remission therapy in older adults with previously untreated acute myeloid leukemia. Haematologica, 97, 739-742. doi:10.3324/haematol.2011.055822

[45] Nand, S., Megan Othus, M., John, E., Godwin, J.E., Willman, C.L., Norwood, T., Erba, H.P., Howard, D., Coutre, S.E. and Appelbaum, F.R. (2012) A Phase II Trial of Azacitidine (NSC-102816) and Gemtuzumab Ozogamicin (NSC-720568) As Induction and Post-Remission Therapy in Patients of Age 60 and Older with Previously Untreated Non-M3 Acute Myeloid Leukemia (SWOG S0703): Report On the Poor Risk Patients. Blood, 120.
[46] Daver, N., Kantarjian, H.M., Garcia-Manero, G., GarciaManero, G., Konopleva, Z.E.M., Burger, J.A., O’Brien, S., Ferrajoli, A., Verstovsek, S., Kadia, T.M., Jabbour, E.J., Faderl, S., Diaz-Pines-Mateo, M., Pemmaraju, N., Pierce, S.A., Cortes, J.E. and Borthakur, G. (2012) Decitabine and gemtuzumab ozogamicin in acute myelogenous leukemia and high-risk myelodysplastic syndrome. Blood, 120.

[47] Lo Coco, F., Ammatuna, E. and Noguera, N. (2006) Treatment of acute promyelocytic leukemia with gemtuzumab ozogamicin. Clinical Advances in Hematology and Oncology, 4, 57-62, 76-77.

[48] Takeshita, A., Shinjo, K., Naito, K., Matsui, H., Sahara, N., Shigeno, K., Horii, T., Shirai, N., Maekawa, M., Ohnishi, K., Naoe, T. and Ohno, R. (2005) Efficacy of gemtuzumab ozogamicin on ATRA- and arsenic-resistant acute promyelocytic leukemia (APL) cells. Leukemia, 19, 1306-1311. doi:10.1038/sj.leu.2403807

[49] Candoni, A., Damiani, D., Michelutti, A., Masolini, P., Michieli, M., Michelutti, T., Geromin, A. and Fanin, R. (2003) Clinical characteristics, prognostic factors and multidrug-resistance related protein expression in 36 adult patients with acute promyelocytic leukemia. European Journal of Haematology, 71, 1-8. doi:10.1034/j.1600-0609.2003.00084.x

[50] Lo-Coco, F., Cimino, G., Breccia, M., Noguera, N.I., Diverio, D., Finolezzi, E., Pogliani, E.M., Di Bona, E., Micalizzi, C., Kropp, M., Venditti, A., Tafuri, A. and Mandelli, F. (2004) Gemtuzumab ozogamicin (Mylotarg) as a single agent for molecularly relapsed acute promyelocytic leukemia. Blood, 104, 1995-1999. doi:10.1182/blood-2004-04-1550

[51] Ravandi, F., Estey, E., Jones, D., Faderl, S., O'Brien, S., Fiorentino, J., Pierce, S., Blamble, D., Estrov, Z., Wierda, W., Ferrajoli, A., Verstovsek, S., Garcia-Manero, G., Cortes, J. and Kantarjian, H. (2009) Effective treatment of acute promyelocytic leukemia with all-trans-retinoic acid, arsenic trioxide, and gemtuzumab ozogamicin. Journal of Clinical Oncology, 27, 504-510. doi:10.1200/JCO.2008.18.6130

[52] Aribi, A., Kantarjian, H.M., Estey, E.H., Koller, C.A., Thomas, D.A., Kornblau, S.M., Faderl, S.H., Laddie, N.M., Garcia-Manero, G. and Cortes, J.E. (2007) Combination therapy with arsenic trioxide, all-trans retinoic acid, and gemtuzumab ozogamicin in recurrent acute promyelocytic leukemia. Cancer, 109, 1355-1359. doi: $10.1002 /$ cncr. 22524 